\title{
Relation between antinuclear antibodies and the autoimmune rheumatic diseases and disease type and activity in systemic lupus erythematosus using a variety of cultured cell lines
}

\author{
J Sequi, I Leigh, D A Isenberg
}

\begin{abstract}
Antinuclear activity was assessed in serum samples from a series of $\mathbf{4 0}$ patients with differing clinical subsets (including renal and neurological disease) of systemic lupus erythematosus (SLE) against a transformed keratinocyte line (SvK14)* and normal human keratinocytes. Paired serum samples were studied during disease activity and inactivity, and the effects of ultraviolet radiation on the availability of nuclear antigens in the cell substrates were assessed. Serum samples from 20 healthy controls and 40 disease controls, comprising 10 patients each with rheumatoid arthritis, Sjögren's syndrome, scleroderma, and myositis, were also studied. The keratinocytes all provided sensitive substrates for the detection of antinuclear antibodies (ANAs), and in normal keratinocytes treated with ultraviolet radiation nuclear antigens were exposed on the cell surface. There was no correlation between ANAs and disease activity or patterns so, apart from assisting diagnosis, the detection of ANAs is of little relevance to predicting disease activity.
\end{abstract}

In an earlier study of patients with discoid lupus erythematosus it was shown that the use of several cultured human epithelial cells, including keratinocytes, improved the sensitivity of detecting antinuclear antibodies (ANAs). ${ }^{1}$ In addition, it was found that the titre and pattern of ANA staining were notably substrate dependent: transformed keratinocytes were shown to be more sensitive than primary keratinocytes. This is likely to reflect alteration in the antigenicity of the cells after transformation.

This study extends the original study by increasing the types of cell lines used and the variety of patients studied. Serum samples from up to 20 healthy controls, 40 patients with systemic lupus erythematosus (SLE), and 10 each with rheumatoid arthritis, Sjögren's syndrome, scleroderma, and adult onset myositis were analysed. The relation between ANA reactivity and the several subgroups of lupus patients was analysed. Furthermore, within each subgroup samples obtained during both inactive and active phases of the disease were studied.

The cutaneous signs of lupus erythematosus are often triggered by ultraviolet irradiation and in vivo ultraviolet radiation seems to increase the binding of anti-Ro antibodies to the dermoepidermal junction and basal keratinocytes. ${ }^{2}$
LeFeber et al studied the binding of lupus autoantisera to keratinocytes which had been ultraviolet irradiated. ${ }^{3}$ They reported that ultraviolet irradiation induced expression of nuclear antigens on the keratinocyte cell surface. Thus the ANA reactivity of our test sera was examined against normal human epidermal keratinocytes non-irradiated or subjected to 30 seconds or one minute of ultraviolet irradiation. An Sv40 transformed keratinocyte line SvK14 cells had previously been used ${ }^{1}$ and was found to be more sensitive than normal untransformed keratinocytes as a substrate for ANA testing. A clone treated with high doses of ultraviolet irradiation was obtained (UVK14) and showed altered growth characteristics compared with the parent line. The antisera were therefore tested against both SvK14 and the ultraviolet treated line UVK14 to determine whether ultraviolet irradiation had altered the distribution or expression of nuclear antigens. The standard epithelial cell line for ANA testing (HEp-2) was assessed as a control.

\section{Patients, materials, and methods} PATIENTS

Forty patients with SLE (38 female, two male) were studied. Each met four or more of the American Rheumatism Association's (ARA) revised criteria for the disease. ${ }^{4}$ From this group eight patients each were selected who had primarily $(a)$ renal disease; $(b)$ central nervous system disease; $(c)$ joint and skin disease only; (d) pleuropericardial symptoms; and (e) deep venous thrombosis with recurrent thrombosis or spontaneous abortions, or both, and thrombocytopenia accompanied by anticardiolipin antibodies. Details of the criteria for the organ or system affected have been published elsewhere. ${ }^{5}$ For each of these 40 patients one blood sample taken during disease remission and one during active disease were selected for study. Disease activity was graded according to a previously published index ${ }^{6}$ which has recently been validated with an activity index generated by a more detailed, computer based programme. ${ }^{7}$

As disease controls serum samples were taken from 10 patients each with rheumatoid arthritis (eight female, two male diagnosed according to the revised criteria of the $\mathrm{ARA}^{8}$ ); primary Sjögren's syndrome (eight female, two male diagnosed by the criteria of Isenberg $e t$ $a l^{\vartheta}$ ); adult onset myositis (seven female, three male, each of whom met three or four of the criteria of Bohan and Peter ${ }^{10}$ ); and scleroderma 
Table 1 General pattern of reactivity with the SvK14, UVK14 and HEp-2 cell lines. ${ }^{*}$ Results are given as numbers (\%)

\begin{tabular}{|c|c|c|c|c|c|c|c|c|c|}
\hline & \multicolumn{3}{|l|}{ Nucleus } & \multicolumn{3}{|c|}{ Nucleolus } & \multicolumn{3}{|c|}{ Cytoplasm } \\
\hline & $S v K 14$ & $U V K 14$ & $H E p-2$ & $S v K 14$ & $U V K 14$ & $H E p-2$ & $S v K 14$ & $U V K 14$ & $H E p-2$ \\
\hline $\begin{array}{l}\text { SLE† } \\
\text { Renal }(n=8) \\
\text { CNS } \dagger(n=8) \\
\text { Arthralgia }(n=8) \\
\text { Pleuropericardial }(n=8) \\
\text { DVT† }(n=8) \\
\text { SLE total }(n=40) \\
\text { RAt }(n=10) \\
\text { Siögren's syndrome }(n=10) \\
\text { Scleroderma }(n=10) \\
\text { Myositis }(n=10) \\
\text { Healthy controls }(n=20)\end{array}$ & $\begin{array}{c}7 \\
7 \\
7 \\
7 \\
4 \\
32 \quad(80) \\
2 \ddagger(20) \\
7(70) \\
5(50) \\
4(40) \\
1 \neq(5)\end{array}$ & $\begin{array}{r}7 \\
7 \\
7 \\
7 \\
4 \\
32(80) \\
1 \ddagger(10) \\
7(70) \\
4(40) \\
7(70) \\
4 \ddagger(20)\end{array}$ & $\begin{array}{rr}8 & \\
8 & \\
8 & \\
8 & \\
8 & \\
40 & (100) \\
10 & (100) \\
7 & (70) \\
7 & (70) \\
9 & (90) \\
3 \ddagger & (15)\end{array}$ & $\begin{array}{l}2 \\
2 \\
0 \\
1 \\
0 \\
5(12 \cdot 5) \\
0 \\
2(20) \\
5(50) \\
1(10) \\
0\end{array}$ & $\begin{array}{l}2 \\
3 \\
1 \\
2 \\
2 \\
10(25) \\
0 \\
0 \\
5(50) \\
1(10) \\
0\end{array}$ & $\begin{array}{l}2 \\
2 \\
2 \\
1 \\
2 \\
9(22 \cdot 5) \\
0 \\
4(40) \\
5(50) \\
1(10) \\
0\end{array}$ & $\begin{array}{l}3 \\
2 \\
3 \\
1 \\
0 \\
9(22 \cdot 5) \\
0 \\
4(40) \\
0 \\
0 \\
0\end{array}$ & $\begin{array}{l}1 \\
3 \\
3 \\
3 \\
1 \\
11(27 \cdot 5) \\
0 \\
4(40) \\
0 \\
0 \\
0\end{array}$ & 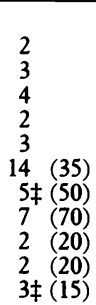 \\
\hline
\end{tabular}

*In the group with systemic lupus erythematosus the patterns are those found during active disease.

tSLE=systemic lupus erythematosus; $\mathrm{CNS}=$ central nervous system; DVT=deep venous thrombosis; $\mathrm{RA}=$ rheumatoid arthritis. $\ddagger$ Weak positive only.

Table 2 Relation between the intensity of nuclear staining and disease activity in the 40 patients with systemic lupus erythematosus

\begin{tabular}{|c|c|c|c|c|c|c|}
\hline \multirow{2}{*}{$\begin{array}{l}\text { Patients with } \\
\text { SLE* } \\
\text { ( } 8 \text { in each group) }\end{array}$} & \multicolumn{3}{|l|}{$S v K 14$} & \multicolumn{3}{|l|}{ UVK14 } \\
\hline & No change & $\uparrow$ When active & $\uparrow$ When inactive & No change & $\uparrow$ When active & $\uparrow$ When inactive \\
\hline $\begin{array}{l}\text { Renal disease } \\
\text { CNS }^{*} \text { disease } \\
\text { Arthralgia } \\
\text { Pleuropericarditis } \\
\text { DVT }\end{array}$ & $\begin{array}{l}4 \\
3 \\
2 \\
3 \\
2\end{array}$ & $\begin{array}{l}3 \\
3 \\
4 \\
1\end{array}$ & $\begin{array}{l}1 \\
2 \\
2 \\
5 \\
5\end{array}$ & $\begin{array}{l}1 \\
5 \\
5 \\
3 \\
3\end{array}$ & $\begin{array}{l}4 \\
2 \\
1 \\
3 \\
1\end{array}$ & $\begin{array}{l}3 \\
1 \\
2 \\
2 \\
4\end{array}$ \\
\hline
\end{tabular}

${ }^{*}$ SLE=systemic lupus erythematosus; $\mathrm{CNS}=$ central nervous system; DVT=deep venous thrombosis.
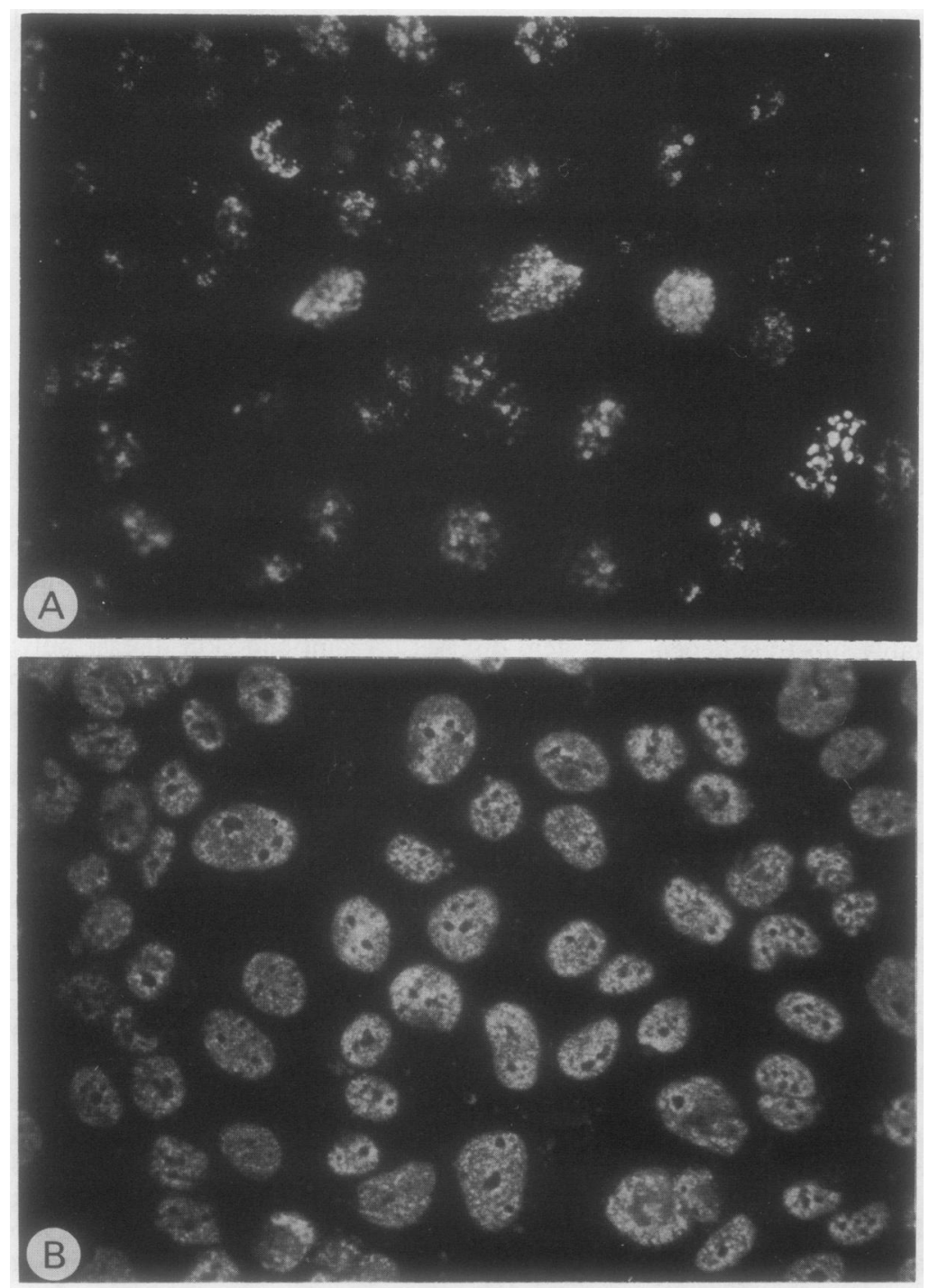

Figure 1 Serum which is anti-DNA positive, anti-RNP, and anticardiolipin positive tested against $(A) S v K 14$ cells and $(B)$ UVK14 cells, illustrating increased sensitivity of UVK14 cells. (nine female, one male diagnosed by the preliminary criteria of the $\mathrm{ARA}^{11}$ ). In addition, serum samples from 20 healthy controls (15 female, five male) were studied. All serum samples were coded and assessed 'blind'.

\section{METHODS}

The cell lines to be used as substrates were prepared as follows:

Sv40 transformed keratinocytes $\left(\mathrm{SvK} 14^{12}\right)$ were cultured in RPMI with $10 \%$ fetal calf serum and passaged weekly after preparation of a single cell suspension by trypsinisation $(0 \cdot 25 \%$ trypsin at $37^{\circ} \mathrm{C}$ for 20 minutes). Samples from early passage numbers (10-25) were subcultured on multiwell slides in drops of medium until near confluence and then air dried.

UVK14 cells A sample of SvK14 cells was irradiated with laboratory ultraviolet radiation for one minute (mineral light source model UV SL 58 254-366), which killed nearly all the cells. The remaining cells were cloned and subcultured, when a strain known as UVK14 was developed which grew more slowly than SvK14 cells (Leigh, unpublished data.) These cells are routinely cultured in RPMI 1640 and $10 \%$ fetal calf serum. Subcultures of this strain were cultured on multiwell slides until near confluence and then air dried.

Normal infantile foreskin non-mucosal keratinocytes were cultured according to the method of Rheinwald and Green ${ }^{13}$ in the presence of 3T3 feeders and added mitogens. ${ }^{14}$ Passages 2 and 3 were subcultured on multichamber slides until preconfluent. Duplicate samples from each culture were treated with 30 seconds and one minute of ultraviolet irradiation from a laboratory source (as above). Cultures were air dried.

Hep-2 cells were cultured on multiwell slides in the presence of Dulbecco's minimum essential medium and $10 \%$ fetal calf serum. 
After air drying all samples were stored at $-70^{\circ} \mathrm{C}$ until use.

\section{Immunocytochemistry}

In the initial screening all 160 serum samples

Table 3 Effect of diluting sera tested on UVK14 and SvK14 cell lines

\begin{tabular}{|c|c|c|c|c|c|}
\hline & $1 / 40$ & $1 / 100$ & $1 / 1000$ & $1 / 5000$ & $1 / 10000$ \\
\hline \multicolumn{6}{|l|}{$\begin{array}{l}\text { Patient No } 1 \\
\text { SvK14 substrate }\end{array}$} \\
\hline Inactive nuclear & + & + & \pm & - & - \\
\hline Active nuclear & ++ & + & + & - & - \\
\hline \multicolumn{6}{|l|}{ UVK14 substrate } \\
\hline Inactive nuclear & + & + & + & - & - \\
\hline Active nuclear & ++ & ++ & ++ & + & \pm \\
\hline \multicolumn{6}{|l|}{$\begin{array}{l}\text { Patient No } 2 \\
\text { SvK14 substrate }\end{array}$} \\
\hline Inactive nuclear & + & + & + & + & - \\
\hline Inactive membrane & + & - & - & - & - \\
\hline Active nuclear & + & + & + & - & - \\
\hline \multicolumn{6}{|l|}{ UVK14 substrate } \\
\hline Inactive nuclear & ++ & ++ & + & + & - \\
\hline Active nuclear & ++ & ++ & \pm & - & - \\
\hline \multicolumn{6}{|l|}{$\begin{array}{l}\text { Patient No } 3 \\
\text { SvK14 substrate }\end{array}$} \\
\hline Inactive nuclear & + & \pm & - & - & - \\
\hline Active nuclear & ++ & + & - & - & - \\
\hline \multicolumn{6}{|l|}{ UVK14 substrate } \\
\hline Inactive nuclear & +++ & ++ & - & - & - \\
\hline Active nuclear & ++ & ++ & - & - & - \\
\hline Active cytoplasmic & \pm & \pm & - & - & - \\
\hline
\end{tabular}
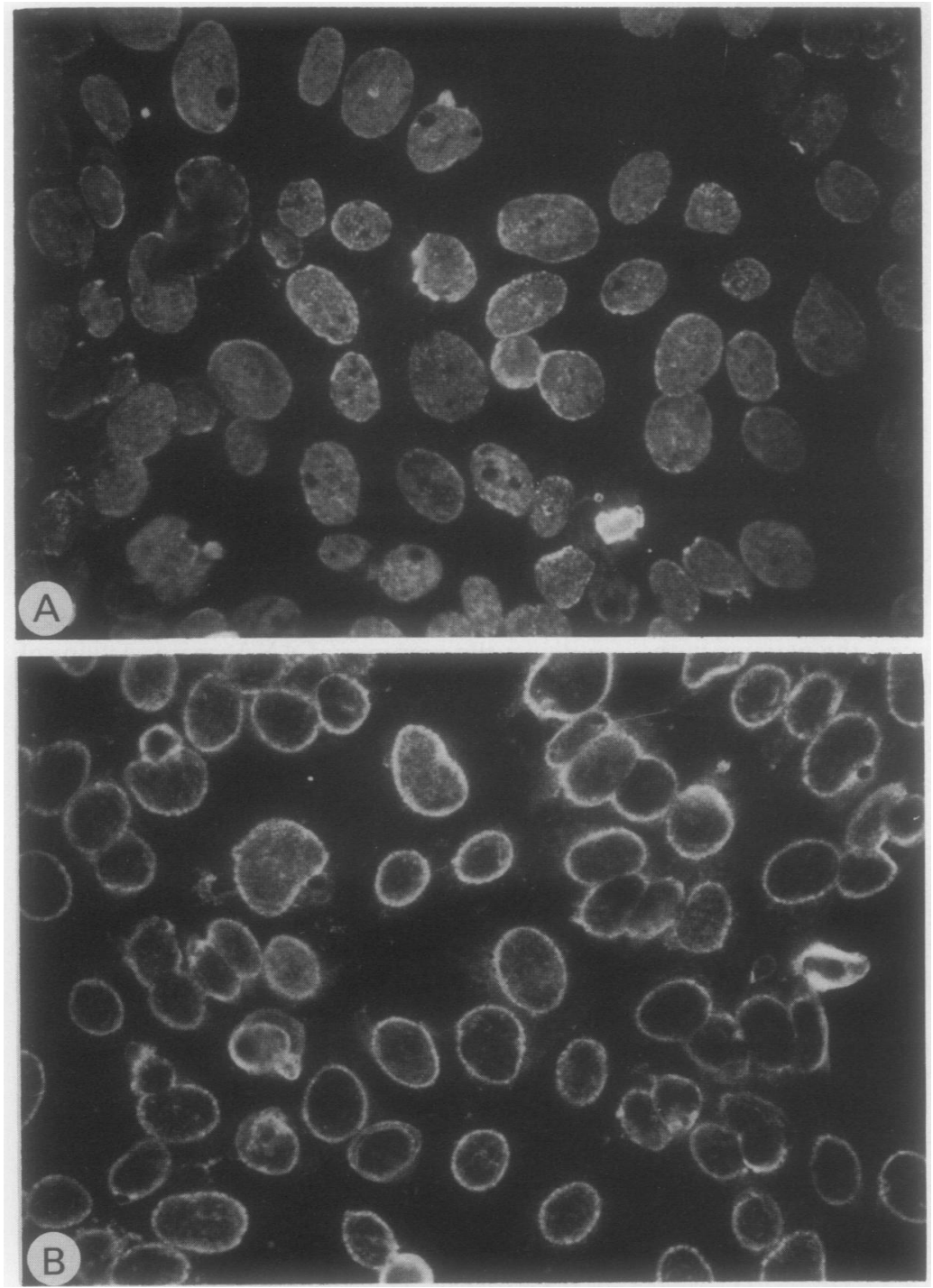

Figure 2 Serum from a patient with a DNA positive Coombs' test showing a change from nuclear staining $(A) S v K 14$ cells to perinuclear $(B) U V K 14$ cells. were tested at a dilution of $1 / 80$ in phosphate buffered saline using the SvK14, UVK14, and HEp-2 cell lines. After incubation at room temperature for 30 minutes the test slides were washed three times with phosphate buffered saline, and fluorescein conjugated $F\left(a^{\prime}\right)_{2}$ fragments of rabbit immunoglobulin to human IgG (Dako) (1/25) were added. The sections were examined under a microscope (Nikon (Optiplot) Episcopic for the UVK14 and SvK14 cells and a Zeiss photomicroscope 2 (West Germany) for the HEp- 2 cells) and graded $0, \pm$ (weak), + (moderate), ++ (strong), or +++ (very strong); the pattern of reactivity was also noted. Slides were coded and read blind.

As described in the 'Results' section 20 of the serum samples found to give the strongest positive reaction were further studied by serial dilutions (to $1 / 10000$ if necessary), and most were also studied using the other cell lines as substrates.

\section{Results}

Tables 1 and 2 show the positive results of the initial screening of all the 160 serum samples tested on the UVK14, SvK14, and HEp-2 cell lines. As the HEp-2 line is the best known and most firmly established the results are focused on a comparison between this substrate and the other two, and on a detailed analysis of the UVK14 and SvK14 lines.

As expected the patients with SLE showed more antinuclear staining-80-100\% with the three cell lines overall-than the other groups. Over $50 \%$ of the serum samples from patients with primary Sjögren's syndrome $(70 \%$ with both lines) and myositis (70\% with the UVK 14 cell line) were also ANA positive. In contrast, nucleolar staining was most commonly found in patients with scleroderma $(50 \%)$ and cytoplasmic staining in the patients with Sjögren's syndrome (40\%).

The subgroup analysis showed little difference between the groups with renal disease, central nervous system disease, arthralgia, or pleuropericarditis for binding to the SvK14 and UVK14 cell lines. Among the group with deep venous thrombosis, however, only $50 \%$ were found to be ANA positive (with the SvK14 and UVK14 lines) and both antinucleolar and cytoplasmic staining were less commonly found.

Among the groups with renal and central nervous system disease most lupus patients showed either increased staining or no change with either cell line in the active compared with the inactive groups (table 2). In contrast, in the groups with pleuropericarditis and deep venous thrombosis the staining was generally strongest during the inactive phase of the disease, especially with the SvK14 cell line as substrate.

Further comparison of the two cell lines showed that the UVK14 substrate often gave stronger staining at the $1 / 80$ dilution (fig 1 ). For example, of the 32 positive active SLE sera, 21 had equal antinuclear staining, 10 scored higher with UVK14 cells, and only one was higher with the SvK14 substrate. This difference was investigated by diluting representative serum samples further from $1 / 40$ to $1 / 10000$. Serum 

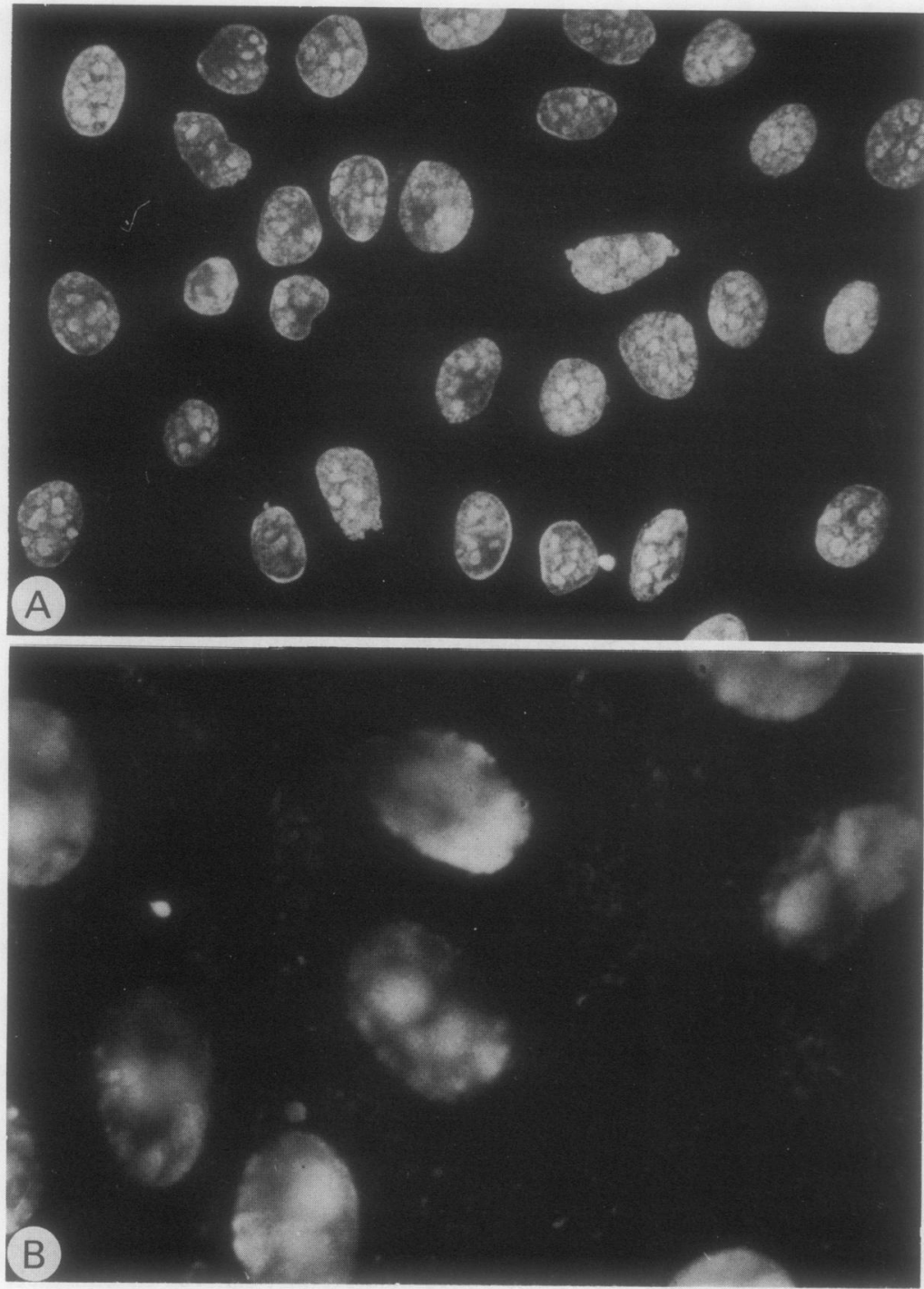

Figure 3 DNA antibody positive serum against (A) SvK14 cells; (B) UVK14 cells to show cytoplasmic staining.
SvK14 cells showed a moderately positive homogeneous appearance (fig 2). In contrast, the UVK14 cells showed enhanced nucleomembrane staining. With other patients staining of the UVK14 cells was more obviously cytoplasmic, as well as nuclear, compared with the SvK14 line (fig 3).

Table 4 provides a comparison of the 20 representative sera tested against the untransformed keratinocytes. Exposure to short bursts of ultraviolet irradiation ( 30 seconds or one minute) did not increase the sensitivity of detection of ANAs in comparison with the other substrates as the number of ANA positive sera was similar, with the healthy sera more obviously unreactive. A change did occur, however, in the pattern of reactivity, with the appearance of membrane particulate staining in $45 \%$ of sera tested on keratinocytes irradiated for one minute and in $20 \%$ of sera irradiated for 30 seconds, whereas no controls or test sera showed any membrane staining on non-irradiated cells. The presence of cytoplasmic staining was increased from 30 to $65 \%$ of sera on the cells irradiated for 30 seconds.

Membrane particulate staining was seen in the three patients who were Ro/La positive but was also found in six patients who were not Ro/La positive. All these patients were antiDNA positive. The strongest particulate staining (fig 4) was found in a patient who was antiDNA positive and had a positive Coombs' test.

\section{Discussion}

The presence of ANAs is one of the criteria used in the ARA's revised classification of SLE. ${ }^{4}$ Probably fewer than $5 \%$ of lupus patients are ANA negative. Antinuclear antibody reactivity is also found, however, in all of the other autoimmune rheumatic diseases and a variety of infectious diseases. ${ }^{15} 16$ This is not surprising given the wide variety of potential antigenic determinants in the nucleus. It has proved a major challenge to match the pattern of ANA reactivity with the fine specificity of the antigens. ${ }^{17}$

For many years the standard substrates used to detect the presence of ANAs were sections of rat liver or mouse kidney, but they have been reported to lack sensitivity. For example, in a study of 114 patients with myositis only 33\% were ANA positive with mouse kidney as substrate, but $78 \%$ were positive with HEp-2. ${ }^{18}$

More recently it has been shown that a broad range of human epithelial cells, including keratinocytes, provide suitable substrates for detecting ANAs. ${ }^{1}$ In this study the HEp-2 cell line and T47D cells, a human breast carcinoma line,

Table 4 Comparison of the patterns of reactivity of the ultraviolet irradiated (1 minute or 30 seconds) keratinocytes. Number (percentage) of patients is shown

\begin{tabular}{|c|c|c|c|c|c|c|c|c|c|}
\hline & \multicolumn{3}{|l|}{ Nucleus } & \multicolumn{3}{|c|}{ Nucleolus } & \multicolumn{3}{|c|}{ Cytoplasm } \\
\hline & At & $B t$ & $C t$ & $\boldsymbol{A}$ & $B$ & $C$ & $A$ & $\boldsymbol{B}$ & $C$ \\
\hline $\begin{array}{l}\text { SLE }(n=20)^{*} \\
\text { Disease controls }(n=7) \\
\text { Healthy controls }(n=5)\end{array}$ & $\begin{array}{l}14(70) \\
4(57) \\
0\end{array}$ & $\begin{array}{l}16(80) \\
\text { NTt } \\
0\end{array}$ & $\begin{array}{l}17(85) \\
4(57) \\
0\end{array}$ & $\begin{array}{l}0 \\
2(28 \cdot 5) \\
0\end{array}$ & $\begin{array}{l}0 \\
\text { NT } \\
0\end{array}$ & $\begin{array}{l}0 \\
2(28 \cdot 5) \\
0\end{array}$ & $\begin{array}{l}6(30) \\
2(28 \cdot 5) \\
0\end{array}$ & $\begin{array}{l}13(65) \\
N T \\
0\end{array}$ & $\begin{array}{l}5(25) \\
3(43) \\
0\end{array}$ \\
\hline
\end{tabular}

*In the group with SLE the samples tested were taken from patients during active disease.

$+A=$ untransformed, non-irradiated keratinocytes; $B=$ untransformed keratinocytes exposed to 30 seconds ultraviolet light; $\mathrm{C}=$ untransformed keratinocytes exposed to one minute ultraviolet light; $\mathrm{NT}=$ not tested. 

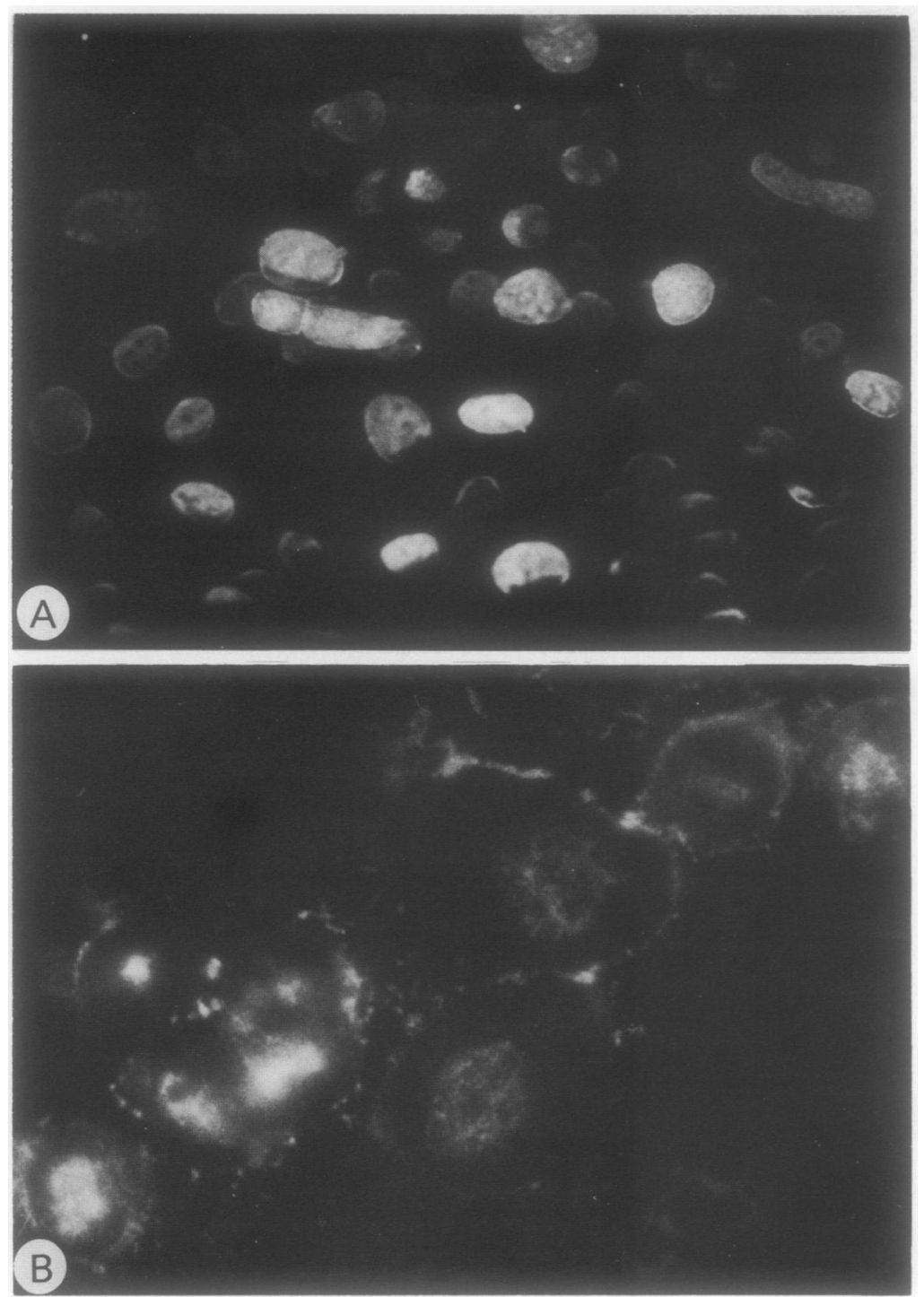

Figure 4 Normal foreskin keratinocytes with same Ro negative serum as fig 2 showing $(A)$ nuclear staining in non-irradiated, non-transformed keratinacytes (as in $2 A$ with SoK 14 cells, but showing $(B)$ particulate membrane staining after one minute's ultraviolet irradiation.

were found to be the most sensitive. This analysis was confined to serum samples from patients with discoid lupus only. Our study has assessed the ANA reactivity across the spectrum of autoimmune diseases with six different substrates.

This study has shown that ANAs are found in a high percentage of patients with connective tissue diseases and that the positivity of reaction is not specifically associated with active disease. The transformed and non-transformed keratinocytes were highly satisfactory for ANA detection.

A number of subtle differences between the various cell lines are noteworthy. For example, the results with the SvK14 and UVK14 irradiated transformed cells showed differences in the strength of reactions (UVK14 cells generally gave a stronger reaction) and even in the pattern of reactivity using the same serum, with perinuclear staining more common in the UVK14 cells. This may, of course, reflect alterations in antigenicity brought about by ultraviolet radiation. This point may not be entirely academic as it is plausible that ultraviolet DNA might be immunogenic in SLE. ${ }^{19}$ Ultraviolet light is, for example, known to induce antigenic determinants by the formation of thymidine dimers. ${ }^{20}$

Previous reports of ANA testing in patients with cutaneous signs of lupus against ultraviolet irradiated non-transformed keratinocytes have suggested that ultraviolet radiation induces membrane expression of SSA/Ro, RNP, and Sm. ${ }^{3}$ We also found particulate membrane staining in $45 \%$ of sera tested after ultraviolet irradiation of normal keratinocytes for one minute. This was not restricted to Ro and $\mathrm{La}$ positive patients but was also found in patients with anti-DNA antibodies. There was an effect dependent on dose, with fewer membrane positives after 30 seconds' irradiation, suggesting an association with epidermal cell damage. The membrane staining in the Ro/La negative patients suggests that ultraviolet irradiation may well induce the appearance at the cell membrane of other antigenic determinants. There was no membrane staining of the UVK 14 cells, but these cells are viable having had previous exposure to ultraviolet radiation during development, and are therefore not strictly comparable. The study of LeFeber $e t$ al showed particulate membrane staining in dying keratinocytes only, with live cells showing no reaction of the membrane. ${ }^{3}$ The only cytoplasmic reactivity in UVK14 cells seemed on close inspection to be perinuclear. Possibly, a combination of transformation and ultraviolet irradiation is important for altering antigenicity. In addition, patients with cutaneous lupus may show clinical photosensitivity and so this may be associated with extranuclear antigenicity and photosensitivity. Dose regimens and time course of exposure of the cell lines may also be important.

In common with other previous studies (reviewed in ref 17) antinucleolar reactivity was largely confined to the serum of patients with scleroderma, and anticytoplasmic staining to this was similar to the spread of positive anticytoplasmic antibodies found with the HEp-2 cell line.

The major conclusion to be drawn from our study is that a high prevalence of ANAs, as detected on a wide variety of cultured human epithelial cells, may be found in all the autoimmune rheumatic diseases. They are thus not disease specific, nor associated with disease activity, and neither does their detection in lupus patients offer a simple guide to the major subgroups of this disease or activity within these subgroups.

1 Leigh I, Wojnarowska F, Burge S, Bhogal B, Zhu T. Use of cultured epithelial cells, including keratinocytes, for the detection of antinuclear antibodies. Ann Rheum Dis 1987; 46: 929-33.

2 Lee L A, Weston W L, Stevens J D, Krueger G G, Emam $M$, Norris D A. Differential in vivo binding of specific lupus sera in human skin [Abstract]. F Invest Dermatol 1985; 85: 339.

3 LeFeber W P, Norris D A, Ryan S R, et al. Ultraviolet light induces binding to selected nuclear antigens on cultured human keratinocytes. F Clin Invest 1984; 74: 1545-9.

4 Tan E M, Cohen A S, Fries J F, et al. The 1982 revised criteria for the classification of systemic lupus erythecriteria for the classification of systemic
matosus. Arheritis Rhewm 1982; 25: 1271-7.

5 Morrow $\dot{W}$ J W, Isenberg D A, Todd Pokropek A, Parry H F, Snaith M L. Useful laboratory measurements in the H F, Snaith M L. Useful laboratory measurements in the
management of systemic lupus erythematosus. $Q f$ Med management of syste.

6 Isenberg D A, Shoenfeld Y, Schwartz R S. Multiple serologic 
reactions and their relationship to clinical activity in systemic lupus erythematosus. Arthritis Rhewm 1984; 27: 132-8.

7 Symmons D P M, Coppock J S, Bacon P A, et al. Development and assessment of a computerised index of clinical disease activity in systemic lupus erythematosus. Q F Med 1988; 69: 927-37.

8 Arnett F C, Edworthy S M, Bloch D A, et al. The American Rheumatism Association 1987 revised criteria for the classification of rheumatoid arthritis. Arthritis Rheum 1988; 31: $315-24$.

9 Isenberg D A, Rowe D, Tookman A, et al. An immunohistological study of secondary Siögren's syndrome. Ann Rheum Dis 1984; 43: 470-6.

10 Bohan A, Peter J B. Polymyositis and dermatomyositis. N Engl f Med 1975; 292: 344-7, 403-7.

11 Masi A T, Rodnan G P, Medsger T A, et al. Preliminary criteria for the classification of systemic sclerosis (scleroderma). Bull Rheum Dis 1981; 31: 1-6.

12 Taylor Papadimitrou J, Purkis P, Lane E B, Mackay I A Chang S E. Effects of Sv40 transformation on the cytoskeleton and behavioural properties of human keratinocytes. Cell Differ Dev 1982; 11: 169-80.

13 Rheinwald J G, Green H. Serial cultivation of strains of human epidermal keratinocytes: the formation of keratinis- ing colonies from single cell suspension. Cell 1975; 6: $331-44$.

14 Leigh I M, Purkis P E, Navsaria H A, Phillips T A Treatment of chronic venous ulcers with sheets of cultured Treatment of chronic venous ulcers with sheets of cultured
allogeneic keratinocytes. $\mathrm{Br} \mathcal{F}$ Dermatol $1987 ; 117: 591-7$.

15 Morrow W J W, Isenberg D A. Autoimmune rheumatic disease. Oxford: Blackwell Scientific, 1987.

16 Isenberg D A, Maddison P, Swana G, et al. Profile of autoantibodies in the serum of patients with tuberculosis, klebsiella and other Gram negative infections. Clin Exp Immunol 1987; 67: 516-23.

17 Tan E M, Chan E K L, Sullivan K F, Rubin R L. Antinuclear antibodies (ANAs): diagnostically specific immune markers and the understanding of systemic autoimmunity. Clin Immunol Immunopathol 1988; 47: 121-41.

18 Reichlin M, Arnett F C Jr. Multiplicity of antibodies in myositis sera. Arthritis Rheum 1984; 27: 1150-6.

19 Davis P, Russell A S, Percy J S. Antibodies to UV light denatured DNA in systemic lupus erythematosus: detection by filter radioimmunoassay and clinical correlations. tion by filter radioimmunoassa
$\mathcal{F}$ Rheumatol $1976 ; 3: 375-9$.

20 Strickland P T, Boyle J M. Characterization of two monoclonal antibodies specific for dimerised and non-dimerised adjacent thymidines in single stranded DNA. Photochem Photobiol 1981; 34: 595-601. 